\section{Australia lifts budget threats to public research}

[CANBERRA] A long-awaited statement on industry policy by Australia's Coalition government has reprieved the Cooperative Research Centres (CRCs) from closure, and dropped a proposal that national research agencies and universities should substantially increase their external earnings.

In addition, recent cuts in government support for industrial research and development have been partially restored, while the board responsible for that programme has escaped abolition.

A major review by the businessman David Mortimer had proposed that funding to the 65 CRCs be cut from an annual A $\$ 146$ million (US\$108 million) to A $\$ 20$ million. But the association of CRCs predicted this would lead to the "devastation" of a programme that combines the work of universities, research agencies and industries in targeted projects. Chief scientist John Stocker attacked Mortimer's recommendation.

Mortimer also wanted the research agencies to increase their external earnings, the largest, the Commonwealth Scientific and Industrial Research Organization (CSIRO), "from 30 to 50 per cent". But the CSIRO's chief executive, Malcolm McIntosh, said Mortimer "used the wrong base" and the change "would cripple strategic research and destroy CSIRO" (see Nature 388, $509 \& 819 ; 1997$.)

Mortimer proposed a billion-dollar investment fund to improve industrial competitiveness. This would have been created partly from cuts to research, and the government's rejection of this idea has allowed the reprieve for science. But some of Mortimer's recommendations have been accepted, notably the setting of an economic growth target which the government has pitched at "over 4 per cent over the decade to 2010".

The package contains several measures costing A $\$ 1.2$ billion over five years. Direct funding of business $\mathrm{R} \& \mathrm{D}$ through a grant scheme called START has been extended by A \$139 million annually to a total of A $\$ 739$ million over four years. The government did not respond to the pleas of industrialists and scientists for restoration of a 150 per cent tax concession for in-house company R\&D. The rate is left at 125 per cent.

The Labor Opposition spokesman on industry, Simon Crean, calculates that funding cuts to $R \& D$ have been $A \$ 2$ billion over the 1996 and 1997 budgets, only a quarter of which have now been restored.

But the industry, science and tourism minister, John Moore, says the START scheme targets "quality R\&D" and the overall policy will "build vibrant, internationally competitive industries".

PeterPockley

\title{
Kyoto meeting bridges gaps, though differences remain
}

[KYOTO] Prospects for a legally binding treaty to reduce greenhouse gas emissions edged a step closer at the beginning of this week as the 10-day United Nations climate conference in Kyoto moved towards its climax on Wednesday (10 December).

But the final outcome remained uncertain, depending on how far the United States was prepared to take a promise to be "flexible" made on Monday by Vice-President Al Gore.

Following eight days of tense discussions, the chairman of the conference, Raul Estrada Ouyela, Argentina's ambassador to China, set out a final consensus proposal, which he described as a "take it or leave it document". The document proposed a treaty in which developed countries would reduce their greenhouse gas emissions by an average 5 per cent from 1990 levels between 2006 and 2010.

This proposal mirrored that of Japan. It was lower than the European Union's proposed 15 per cent reduction from 1990 levels by 2010 , but higher than the US proposal to

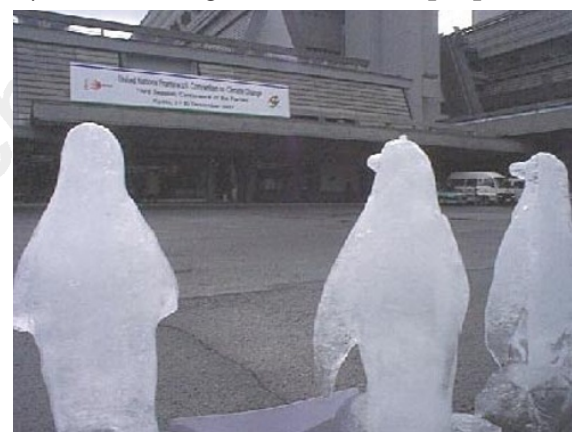

Cold sweat: ice penguins melt in the sun as they await a result from the climate conference hall. stabilize emissions at 1990 levels before 2012 .

Estrada proposed that the treaty should apply to three gases: carbon dioxide, methane and nitrous oxide. A separate protocol, to be negotiated at the next conference of the climate convention, would apply to other greenhouse gases.

The 5 per cent reduction figure is an average for all 39 developed countries that are parties to the convention. It was calculated by a process known as 'differentiation' - the idea that different countries can reduce or increase their emissions according to their circumstances. Most developed countries would have to reduce emissions by 8 per cent, except the United States, Canada and Russia, which are allowed a 5 per cent reduction, and Japan, which is allowed a 4.5 per cent reduction.

In contrast, Australia - which continues to oppose legally binding emissions reduction targets - would be allowed to increase its emissions by 5 per cent. Norway would be permitted to increase emissions by the same amount, and Iceland by 10 per cent.

In a concession to countries such as Canada and New Zealand with large forestry resources, a country's emissions inventory would include both carbon dioxide from fossil-fuel sources and carbon released into the atmosphere from deforestation. This carbon 'subtotal' would then be reduced by the amount of carbon removed from the atmosphere through planting new trees. But a target date for the inclusion of carbon from forests has been deferred until scientists find a more accurate way of measuring the release and uptake of this carbon. Ensan Masood

\section{CERN deal 'historic and path-breaking'}

[WASHINGTON] US and European officials have signed the agreement under which the United States will contribute $\$ 531$ million towards the construction of the Large Hadron Collider at the European Laboratory for Particle Physics (CERN) in Geneva, Switzerland.

“This is the first time we've made an investment like this in a facility outside the United States," said Federico Peña, the US energy secretary, after the signing ceremony at the White House this week. Peña described the deal as "historic and path-breaking".

The US contribution will consist of $\$ 200$ million for the construction of the collider and \$250 million for its two detectors, ATLAS and CMS, from the Department of Energy, and a further $\$ 81$ million for the detectors from the National Science Foundation (see Nature 385, 103; 1997).
Officials paid warm tribute to Sidney Drell, deputy director of Stanford Linear Accelerator Center. In 1994, Drell chaired a panel that identified participation in the Large Hadron Collider project as a top priority for US high-energy physics after Congress had cancelled the Superconducting Super Collider project in Texas, and explained how it could be paid for without disrupting other physics research.

Christopher Llewellyn Smith, director general of CERN, said that the $\$ 6$ billion project will be completed in 2005 , three years earlier than would otherwise have been possible, thanks to the involvement of the United States and Japan. US delegates will attend a meeting of the CERN council next week as observers and will hear that the programme is on time, on budget and "in excellent technical shape". Colin Macilwain 